Filol. linguist. port., n. 14(1), p. 121-140, 2012.

\title{
A noção de Ciência da Informação - uma abordagem terminológica
}

\author{
Jéssica Câmara Siqueira ${ }^{1}$
}

\begin{abstract}
Resumo: A compreensão das características identitárias da Ciência da Informação é uma necessidade conjuntural observada no contexto da pós-modernidade. O estudo parte da análise terminológica do termo Ciência da Informação utilizando o cabedal dos procedimentos de análise e síntese da orientação contemporânea da Teoria Comunicativa da Terminologia. A análise das definições permite a identificação dos principais traços identitários da área, o que busca corroborar uma melhor delimitação do campo da Ciência da Informação.
\end{abstract}

Palavras-chave: Ciência da Informação; Pós-modernidade; Terminologia.

\section{INTRODUÇÃO}

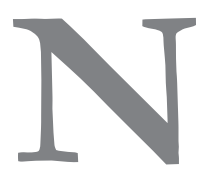

o contexto histórico social contemporâneo, os patamares organizacionais e estruturais da Ciência se abalam com a introdução dos valores da perspectiva científica pós-moderna. Se, por um lado, pode-se supor a possibilidade de que o novo olhar sob a Ciência substitua o integralmente velho, por outro, considera-se que nesse momento de transição eles possam conviver no tempo, caracterizando posturas diferentes frente aos fenômenos estudados. Esse contexto, que não pode ser desconsiderado, implica a necessidade de repensar referências, conceitos, bem como de observar a integração do sujeito plural na produção do conhecimento.

O domínio da Ciência da Informação não é imune às variações que resultam dessa crise dos modelos científicos. Isso leva à necessidade de considerar, entre outros, dois problemas, a tentativa de uma delimitação de seu objeto de estudo, e as divergências geradas dessa discussão, que desembocam

1 Doutoranda em Letras do Programa de Filologia e Língua Portuguesa da Universidade de São Paulo. Mestrado em Ciência da Informação (ECA-USP). Especialização em Arquivos (IEB-USP). E-mail: jessica.camara@yahoo.com.br 
num esforço de definição da área. Mesmo que a ideia de demarcação de um objeto de estudo seja polêmica e cada vez mais questionável no âmbito da mudança de paradigmas, a delimitação do campo é uma necessidade, fato que se caracteriza a partir da circunscrição de sua terminologia.

A Terminologia, como instrumento teórico e metodológico, fornece instrumental para observar as nuances da área da Ciência da Informação sem deixar de observar as variações de uso e sua inserção histórico-cultural. Por meio da identificação de conceitos, termos e definições inscritas nos discursos, é possível verificar as formas de constituição dos domínios, seu desenvolvimento, bem como as relações que estabelecem com domínios fronteiriços.

Lara (1993) ressalta que mais do que contribuir para a identificação dos termos, a importância dos referenciais da Terminologia (teórica e concreta) é fornecer a base para identificar como os termos estão sendo utilizados socialmente. No caso da Ciência da Informação, que tem uma identidade nebulosa, o instrumental terminológico pode contribuir para enxergarmos melhor os traços da área.

Considerando a relevância do estudo terminológico, propõe-se a análise da noção do termo Ciência da Informação, com o objetivo de compreender melhor o escopo da área em questão a partir do instrumental terminológico. Para isso, será utilizada como base teórica a Teoria Comunicativa da Terminologia, que considera o termo como um elemento a ser observado na perspectiva de seu contexto de uso. $\mathrm{O}$ artigo se constitui de três partes: primeiro uma revisão de literatura sobre a Terminologia, que aborda sua definição, breve histórico, funções e principais vertentes; em seguida há um breve panorama da discussão acerca da delimitação do domínio da Ciência da Informação e como a terminologia pode contribuir para a identificação de traços identitários da área; e por fim apresenta-se o resultado da análise terminológica do termo Ciência da Informação.

\section{PRECEITOS TERMINOLÓGICOS}

\subsection{Terminologia: breve histórico e principais vertentes}

Quando se aborda o conceito de Terminologia podemos nos referir basicamente a três noções: a Terminologia como disciplina, voltada ao tratamento 
de termos especializados; a terminologia como prática, constituindo-se como um conjunto de princípios voltados à recopilação de termos; ou a terminologia como um produto, ou seja, conjunto de termos de determinada especialidade, gerado pela prática (Cabré, 2002).

Quanto às origens, a Terminologia traz atrelada à sua concepção e utilização, duas noções: a prática e a delimitação de uma área. A primeira noção é remota, pois desde as civilizações mais antigas, notamos uma necessidade de nomeação de seres e coisas para contextos específicos. Tal ação propiciou tanto o desenvolvimento da comunicação oral humana, contribuindo com as organizações sociais, como serviu de base para o surgimento da expressão escrita, que permitiu o registro e a compilação de termos criados culturalmente. Já a segunda noção, segundo Cabré (1993), surge entre os séculos XVIII e XIX quando os cientistas, preocupados com a proliferação e uso descoordenado de designações, resolvem fixar as denominações científicas, com o intuito de organizar e formalizar as disciplinas.

Mesmo com a prática remota, a sistematização e a fixação de um estatuto científico da Terminologia são recentes. Lineu (1707-1778) foi um dos precursores do estudo terminológico voltado às taxionomias. No século XIX e logo após, com o acelerado desenvolvimento técnico e científico do século XX, a Terminologia se consolidou cientificamente. A Terminologia moderna iniciou-se com os trabalhos de Lotte (1888-1950), da escola soviética, e de Wüster (1897-1977), da escola austríaca. O primeiro estava voltado aos aspectos teóricos e metodológicos da Terminologia, encarando-a como disciplina científica influenciada pela Filosofia. O segundo, influenciado pela Lógica, se preocupava com o tratamento dos dados terminológicos e sua padronização, tomando a Terminologia como uma disciplina autônoma de caráter interdisciplinar, com função de atuar a serviço das demais disciplinas técnico-científicas (Cabré, 1993).

Além dessas duas escolas clássicas, Cabré (1993) também comenta sobre a escola tcheca, mais centrada na Linguística, que considera a Terminologia como um subcomponente do léxico da língua e das linguagens de especialidade. Todavia, das três principais vertentes a que foi responsável pela formulação das normas internacionais de padronização terminológica e serviu de base teórico-metodológica para as linhas de estudo contemporâneas no Ocidente, foi a escola austríaca. Ao contrário da escola soviética, de viés mais filosófico, 
a escola austríaca possuía uma perspectiva mais lógica, o que propiciava o desenvolvimento das normalizações da área. Além disso, o idioma utilizado nos trabalhos de Lotte também foi um fator que prejudicou a expansão de sua pesquisa no Ocidente, sendo que até hoje é pouco conhecida.

$\mathrm{Na}$ atualidade, mesmo reconhecendo a importância da herança da escola de Viena para a delimitação dos pilares terminológicos, critica-se a ênfase normativa da Terminologia clássica. Na perspectiva contemporânea o termo não deve ficar restrito ao âmbito normativo, mas ser analisado em seus diferentes contextos discursivos, o que permite encontrar seu valor como uma unidade significativa de uma área na perspectiva do uso.

Seguindo esses pressupostos, podem-se destacar os seguintes estudos contemporâneos da Terminologia: a Teoria Comunicativa da Terminologia, fruto dos trabalhos de Cabré e seus colaboradores do IULA (Instituto Universitário de Linguística Aplicada, Universidade Pompeu Fabra, de Barcelona) na Espanha; a Socioterminologia, com os trabalhos de Gaudin (França) e Auger (Canadá); a Terminologia Cultural, com Diki-Kidiri (Senegal); a Terminologia Cognitiva, com Temmerman (Bélgica), e ainda diversos trabalhos que se utilizam da Análise do Discurso, a exemplo de Pêcheux (França) e da Linguística Textual de Dijk \& Kintsch (Alemanha), mais voltadas aos aspectos linguísticos, semióticos e pragmáticos (Lara, 2005:5). No âmbito deste trabalho será utilizada a vertente da Teoria Comunicativa da Terminologia, representada por Cabré e os pesquisadores do IULA.

\subsection{O caráter inter- e transdisciplinar da Terminologia}

Considerando-se a Terminologia como uma disciplina teórica e aplicada, observa-se que ela envolve a descrição e o ordenamento do conhecimento, tanto num nível cognitivo como comunicacional, utilizando como elementos-chave conceitos e termos. Compreende o estudo científico dos conceitos e seus respectivos termos considerando seu funcionamento social e sua inter-relação com outras áreas, já que também se constitui como um campo inter- e transdisciplinar (Cabré, 1999).

No contexto interdisciplinar a Terminologia estabelece relações com outras disciplinas (Ciências da Linguagem, Ciências da Comunicação e Ciência Cognitiva). Já no âmbito transdisciplinar muda-se o enfoque, ou seja, é a Ter- 
minologia que participa da constituição de diversas matérias de especialidade, considerando que não se faz ciência sem o aporte terminológico.

Assim, o caráter transdisciplinar é facilmente identificado ao se constatar o valor da Terminologia para a construção de um campo científico. Nesse viés, a Terminologia destaca-se pelo papel de caracterizar uma linguagem especializada a fim de representar a estrutura conceitual de um domínio (Cabré, 1999). Exemplos de tal aplicação são as disciplinas técnico-científicas, que enxergam a terminologia como um conjunto de unidades de comunicação que permitem a transferência do pensamento especializado.

A produção do conhecimento científico se constitui a partir de um tripé epistemológico: a delimitação de um campo de conhecimento, uma metodologia adequada à pesquisa, e uma terminologia própria. No contexto movediço da contemporaneidade, em que convivem referências modernas e pós-modernas, os estudos terminológicos facilitam a delimitação de campos de conhecimento e a identificação de conjuntos de termos próprios de um domínio. Assim, sem a Terminologia, os especialistas não conseguiriam se comunicar, repassar seus conhecimentos, nem representar esse conhecimento de forma organizada (Dias, 2000).

A interface da Terminologia com outros domínios revela que no contexto pós-moderno, caracterizado por diversidade e a multiplicidade de pontos de vista na produção, uso e consumo informacional, torna-se necessário considerar outra perspectiva terminológica, diferente da clássica. Cabré, numa abordagem que acolhe tais valores, aponta as principais características da Terminologia no âmbito do contexto contemporâneo:

La terminología es una materia de base semántica, y los términos son unidades que relacionan el lenguaje y la realidad, que representan objetos de la realidad; con los términos, los individuos expresan e intercambian pensamientos y organizan la estructura de base de una disciplina. La polivalencia de los términos se justifica por su multidimensionalidad (Cabré, 1993:93).

Pelo exposto, nota-se que a Terminologia se constitui como base para a estrutura do conhecimento especializado. No lugar de estruturas fixas e unidirecionais que refletiriam uma organização disciplinar, destaca-se o uso, a partir do qual são incorporados o dinamismo e as inter-relações disciplinares. Considerando tal dimensão, pode-se destacar como exemplo a utilização da Terminologia pela 
Ciência da Informação. A Terminologia pode contribuir tanto na emblemática questão da denominação da Ciência da Informação, ainda muito nebulosa, como auxiliar na identificação das diferentes nuances que configuram a área.

\section{TERMINOLOGIA: SUBSÍDIOS PARA A DELIMITAÇÃO DO DOMÍNIO DA CIÊNCIA DA INFORMAÇÃO}

Atualmente, num cenário de ambiguidade e fragmentações, o modelo de racionalidade científica se transforma e com isso assume novas perspectivas. As Ciências Duras, ${ }^{2}$ por exemplo, outrora consolidadas pelo rigor científico, especialização e objetividade, se veem desestabilizadas por terem de ponderar a relatividade, a subjetividade e a pluralidade de condições da conjuntura científica contemporânea (Santos 1987 :45).

No âmbito das Ciências Sociais Aplicadas tal confluência de paradigmas também é notória, visto que elas possuem diversos campos filhos da pós-modernidade, mas que ainda carregam a herança disciplinar e metodológica da modernidade. A Ciência da Informação, por exemplo, por realizar diálogos e trocas interdisciplinares vive um impasse: por um lado amplia seu campo de atuação, trabalhando não com assuntos determinados, mas com problemas; mas por outro lado, por ter nascido num momento de transição de modelos científicos traz em seu bojo traços da modernidade.

Nesse ponto entra em cena a linguagem. Diferentemente da ideia simplista de associar a linguagem a um mero instrumento de codificação passa-se a associá-la à cultura, que desempenha um relevante papel na representação dos processos sociais e na geração de sentido. Considerando a linguagem como uma ampla faculdade humana que integra produção, recepção, pensamento e expressão, tanto numa dimensão individual quanto social (Paveau; Sarfati, 2006), fica mais fácil identificar sua ação concreta no domínio da Ciência da Informação.

2 Segundo Wazlawick (2010), as ciências duras seriam aquelas com maior rigor científico em suas observações, experimentos e deduções, a exemplo da Lógica e da Matemática. Já as ciências ditas "moles", ou "leves", costumam aceitar como evidências dados anedóticos e estudos de caso. 
A importância da Linguagem na Ciência da Informação é objeto da Linguística Documentária, que se preocupa com o estabelecimento dos princípios teóricos e metodológicos da linguagem documentária, encarregando-se de estudar as estruturas simbólicas da Documentação, bem como as formas mediadoras informacionais entre emissores e receptores (Tálamo; Lara, 2006). A Linguística Documentária integra princípios da Terminologia, procurando apoio para a identificação de termos e conceitos correspondentes, bem como sua organização em domínios e áreas de atividade. A Terminologia (teórica) e a terminologia (concreta) apoiam a construção de linguagens documentárias.

A Linguística Documentária reconhece que, para resolver os problemas da informação, é preciso buscar respostas nas Ciências da Linguagem. Assim, para desenvolver-se, busca subsídios na Linguística Estrutural, Semiótica e campos afins, como na Análise do Discurso e nas Ciências Cognitivas (Tálamo, 2001). Da Linguística Estrutural, por exemplo, a Linguística Documentária se apropria do arcabouço teórico do sistema de estrutura linguística, com destaque para os aspectos de arbitrariedade, a estruturação relacional, e a ideia de convenção/representação da língua. Já a Semiótica contribui com a noção do sistema de signos, base para os processos comunicacionais e de significação, e que corrobora a constituição de um signo documentário (Tálamo; Lara, 2006).

Mesmo com importantes contribuições, nem a Linguística nem a Semiótica, bases da Linguística Documentária, resolvem a questão da delimitação temática e funcional da Ciência da Informação, pois não oferecem um instrumental concreto. Não obstante, a Terminologia preenche tal lacuna, já que aborda tanto aspectos teórico-metodológicos, contribuindo na formulação de redes lógico-semânticas, como práticos, fornecendo referencial para a seleção de descritores ou mesmo oferecendo suporte para os procedimentos da linguagem documentária (Tálamo, 2001).

$\mathrm{O}$ uso da terminologia concreta permitiu a possibilidade de conferir um valor mais pragmático aos descritores, que até então eram fortemente influenciados pela Terminologia clássica, voltada à normatização. Mesmo considerando a pertinência dessa vertente tradicional, principalmente por ter contribuído para a elaboração das normas terminológicas internacionais (ISO 704-2000 e ISO 1087/1-2000) e outros textos de base teórica, havia necessidade, ao se considerar a perspectiva interdisciplinar e a pluralidade dos pontos de vista de produção, uso e consumo informacional na atualidade, de 
uma terminologia voltada às questões heterogêneas do uso dos termos em um contexto (Lara, 2006).

Dessa forma, notamos que o uso de referenciais terminológicos na Ciência da Informação não é apenas de caráter normalizador, mas considera o contexto do uso. Assim, como observa Lara (2006:5):

O diálogo entre as áreas supõe, hoje, que o conhecimento não é dado, mas produto da interpretação, o que solicita que as bases da interlocução não releguem a multiplicidade das possibilidades de organização conceitual urdidas nos espaços de atuação ou nas comunidades científicas (Lara, 2006:5).

Smit, Tálamo e Kobashi (2001) ressaltam que considerando o cenário pós-moderno, a discussão acerca das conceituações e das interfaces da Ciência da Informação com outras áreas do conhecimento torna-se relevante. O trabalho terminológico teria, nessa conjuntura, o importante papel de auxiliar na reintrodução do significado oculto da natureza identitária da Ciência da Informação. Nesse viés, o reconhecimento dos conceitos próprios da área contribuiria com a melhor delimitação de características, objetivos e funções da Ciência da Informação. E segundo as autoras, tal caminho facilitaria a descoberta da área e não a mera demonstração do que ela seria.

Todavia tal descoberta pode enfrentar alguns percalços. As autoras lembram que a ausência de um assentamento conceitual, ou mesmo a presença de ambivalências semânticas criam um retardamento teórico, que impede avanços na área. A terminologia, nesse sentido, se usada na perspectiva clássica, a partir da delimitação de denominações, estabeleceria um vocabulário monorreferencial de uma especialidade. Porém, considerando as nuances da perspectiva contemporânea que incorpora a questão do uso, tal delimitação conceitual também pode acontecer, desde que se considere o contexto como elemento-chave para resolver tais impasses. Dessa forma, verificamos que a Terminologia, tanto em sua faceta clássica como nas nuances contemporâneas fornece subsídios para a identificação de conceitos e traços que contribuam para o delineamento do campo da Ciência da Informação. 


\section{ANÁliSE TERMINOLÓGICA DO TERMO "CIÊNCIA DA INFORMAÇÃO”}

\subsection{Procedimentos metodológicos}

Os critérios utilizados para a delimitação do corpus foram de natureza cronológica e geográfica. Foram selecionados artigos científicos dos últimos vinte anos, sendo metade da década de 90 e outra metade da década de 2000. Quanto à delimitação geográfica, optou-se por escolher autores da linha americana, da linha francesa e brasileiros.

Partiu-se do princípio de que a Terminologia tem instrumental para identificar os conceitos, termos e sua organização sistêmica em domínios. Se do ponto de vista teórico, a Terminologia oferece princípios para a análise terminológica, do ponto de vista do método, a Terminografia oferece ferramentas concretas para o desenvolvimento do trabalho.

Para a análise terminológica foi considerada a vertente contemporânea da Teoria Comunicativa da Terminologia, representada por Cabré e seus colaboradores do IULA. Um dos diferenciais dessa perspectiva contemporânea é verificar que o termo não deve ficar restrito ao âmbito normativo - visão da Terminologia clássica -, mas deve ser analisado em seus diferentes contextos discursivos. Dessa forma, o termo encontra seu valor como uma unidade significativa de uma área na perspectiva do uso, ressaltando assim o aspecto contextual.

A primeira fase da pesquisa voltou-se ao levantamento bibliográfico para a construção do corpus: o corpus de trabalho propriamente dito e o corpus de apoio. Selecionados, iniciou-se a segunda fase do trabalho que se constituiu da leitura e coleta de termos, quando foram utilizados procedimentos terminográficos para o preenchimento de fichas terminológicas de cada termo. A terceira fase compreendeu a análise terminológica propriamente dita, com a separação das características ou atributos dos termos e sua comparação utilizando fichas de síntese. E a partir das sínteses foi possível verificar como as noções analisadas corroboram o escopo da Ciência da Informação.

Quanto à análise terminológica propriamente dita, para os procedimentos de coleta e registro dos termos em fichas terminográficas, foram combinadas as sugestões de duas autoras: Cabré e Barros. Barros (2004:18) fala de dois 
tipos de ficha, as de referências e as terminológicas, sendo que esta última se subdivide em: ficha de trabalho, síntese e remissiva. Para Cabré (1993:25) há três tipos de materiais: os de consulta, os destinados especificamente ao trabalho terminográfico e os de suporte, sendo este último subdividido em: fichas de coleta, terminológica, de correspondência e de consulta.

$\mathrm{Na}$ ficha de coleta foram considerados os seguintes elementos: identificação do termo, idioma, fonte do termo e contexto. $\mathrm{Na}$ ficha de análise, além dos elementos anteriores, foi feito o cotejamento do contexto, analisando suas partes seccionadas em características, sintetizadas pelas entradas: natureza interdisciplinar; ciência aplicada; ligação com a Tecnologia; estar focada em temas e problemas; ter como objeto a noção de informação e a dimensão social e cultural. E quanto à ficha de síntese, a partir do quadro relacional entre os diferentes contextos selecionados, foi elaborada uma proposta de definição que procurou sintetizar as principais características analisadas.

Por fim, é relevante salientar aqui a escolha pelo termo "noção" ao invés de conceito. Considerando que a composição dos traços semânticos do termo Ciência da Informação tem uma perspectiva mais dinâmica e inter-relacional, falar de conceito poderia sugerir uma delimitação ou até uma restrição conceitual. Já o termo "noção", proveniente da tradição francesa, está ligado a uma acepção mais genérica e aberta (Rey, 1979:28), perspectiva mais conveniente para o tipo de análise que nos propomos a realizar neste trabalho.

\subsection{Análise terminológica}

A noção de Ciência da Informação em sua origem estava muito atrelada à recuperação da informação e aos sistemas de comunicação da informação, fruto do contexto histórico do final da década de 60. Nesse momento era latente o desenvolvimento de instrumentos que auxiliassem tanto na organização, como na recuperação da informação produzida. Na definição de Borko (1968), considerada clássica para a área, pode-se averiguar os aspectos mencionados anteriormente:

A Ciência da Informação investiga as propriedades e o comportamento da informação, as forças que governam seu fluxo e os meios de processamento para otimizar sua acessibilidade e utilização. Relaciona-se com o corpo de conhecimento relativo à produção, coleta, organização, armazenagem, recuperação, interpretação, transmissão, transformação e utilização da informação (BORKO, 1968:13). 
$\mathrm{Na}$ década de 80 ocorrem outras importantes influências na área, a exemplo da inserção da Administração em seu escopo, bem como a extensão de seu papel nos processos comunicacionais. Fosket (1980) traz outra definição, que também se tornou clássica para a área, e que reflete bem o espírito desse momento:

Uma disciplina surge de uma fertilização cruzada de ideias que incluem a velha arte da biblioteconomia, a nova arte da computação, as artes dos novos meios de comunicação e aquelas ciências como psicologia e linguística que, em suas formas modernas, têm a ver diretamente com todos os problemas da comunicação - a transferência do conhecimento organizado (Foskett, 1980:64).

Com base no exposto sobre a noção de Ciência da Informação, partimos para a análise terminológica. Os autores selecionados, considerando os critérios anteriormente mencionados, foram: da decada de 90 Wersig (1991), Saracevis (1995), Gomez(1990) e Pinheiro e Loureiro(1995); e na década de 2000 Le Coadic(2004), Capurro e Hjorland(2007), Araújo(2003) e Miranda (2002). Abaixo o quadro resumido da ficha de análise:

\begin{tabular}{|c|c|c|c|c|c|c|}
\hline Autor/ano & $\begin{array}{c}\text { Caract.1 } \\
\text { Interdisci- } \\
\text { plinar }\end{array}$ & $\begin{array}{c}\text { Caract. 2 } \\
\text { Ciência } \\
\text { aplicada }\end{array}$ & $\begin{array}{c}\text { Caract. 3 } \\
\text { Ligação } \\
\text { com a } \\
\text { Tecnologia }\end{array}$ & $\begin{array}{c}\text { Caract. 4 } \\
\text { Está focada } \\
\text { em temas e } \\
\text { problemas }\end{array}$ & $\begin{array}{c}\text { Caract. 5 } \\
\text { jeto é a } \\
\text { informação }\end{array}$ & $\begin{array}{c}\text { Caract. 6 } \\
\text { Dimensão } \\
\text { social e } \\
\text { cultural }\end{array}$ \\
\hline $\begin{array}{c}\text { Wersig } \\
(1991)\end{array}$ & + & + & - & + & - & + \\
\hline $\begin{array}{c}\text { Saracevic } \\
(1995)\end{array}$ & + & + & + & + & - & + \\
\hline $\begin{array}{c}\text { Gomez } \\
(1990)\end{array}$ & + & + & - & + & - & + \\
\hline $\begin{array}{c}\text { Pinheiro } \\
\text { Loureiro } \\
(1995)\end{array}$ & + & + & + & + & + & + \\
\hline $\begin{array}{c}\text { Miranda } \\
\text { (2002) }\end{array}$ & + & + & + & - & + & + \\
\hline $\begin{array}{c}\text { Araújo } \\
(2003)\end{array}$ & + & + & - & - & + & + \\
\hline $\begin{array}{c}\text { Le Coadic } \\
\text { (2004) }\end{array}$ & + & + & + & - & + & + \\
\hline $\begin{array}{c}\text { Capurro } \\
\text { Hjorland } \\
\text { (2007) }\end{array}$ & + & + & + & + & + \\
\hline
\end{tabular}

Quadro 1- Quadro resumido da ficha de análise Fonte: (Elaboração da autora) 
Wersig (1991), em seu texto Ciência da Informação: estudo do uso pós-moderno do conhecimento, discute o papel da ciência da Informação no contexto pós-moderno, e como esse contexto influencia na determinação do escopo dessa área. Diferentemente de autores anteriores, que destacavam apenas seu caráter interdisciplinar e sua proximidade com as novas tecnologias, Wersig (1991) focaliza em sua abordagem dois aspectos: o fato de a Ciência da Informação não ter um objeto único, e por isso partir de temas e problemas; e consequentemente poder ser vista numa dimensão prática, já que parte de situações concretas.

Contudo, para chegar às constatações acima, o autor inicia sua reflexão observando como a própria abordagem científica se alterou nos últimos anos do século passado. De uma Ciência delimitada por paradigmas, divisão disciplinar e o tripé estrutural para sua constituição - metodologia, terminologia e um objeto de estudo -, passa-se para um fazer científico que parte de problemas e que é influenciado pelas fragmentações, subjetividades e complexidades do olhar contemporâneo.

Tais parâmetros são os elementos essenciais para que o autor aponte a mudança no papel do conhecimento, de uma dimensão mais filosófica, para uma dimensão tecnológica. A tecnologia para ele, ao contrário de outros autores que se deslumbram com suas potencialidades, é vista com cautela, já que em seu bojo traz a despersonalização e fragmentação do conhecimento, exigindo que sejamos mais críticos com as tecnologias de apropriação e manipulação.

A Ciência da Informação, inserida nesse contexto de mudanças do fazer científico, reflete em seu escopo as idiossincrasias desse momento. Não pode ser vista como uma ciência clássica, já que não possui um objeto único e sua terminologia dialoga com as de outras áreas. Mas também não pode ser reduzida a uma disciplina, já que está voltada à solução de problemas concretos e ainda tem um trabalho interconceitual, o que lhe confere uma nova perspectiva para se enxergar o fazer científico.

Saracevic (1995), outro renomado autor da área, em sua definição sobre Ciência da Informação destaca que houve uma evolução do conceito. Para ele, o núcleo da noção de Ciência da Informação não está restrito à recuperação da informação, mas relaciona-se aos diferentes processos de comunicação do conhecimento, que para ele estão diretamente relacionados ao imperativo tecnológico. 
Nesse viés, o autor ressalta que a Ciência da Informação parte das necessidades informacionais de um determinado contexto social e institucional, o que lhe confere uma dimensão de uma ciência social aplicada. Além dessa dimensão mais social, o autor enfatiza seu caráter interdisciplinar, aspecto que para ele tornou-se mais evidente ao observar a variedade de profissionais que atuam na área, bem como as potencialidades de aplicação de seu arcabouço científico em outras áreas, como a Biblioteconomia, Ciência da Computação, Ciência Cognitiva e Ciência da Comunicação (Saracevic, 1995).

Como Wersig (1991), destaca a necessidade de resolução de problemas, por ser uma ciência social aplicada. Porém ao contrário de Wersig (1991), Saracevic (1995) ressalta o papel das novas tecnologias de informação, como elementos-chave da Ciência da Informação, na resolução de problemas e atrelado ao bojo das novas áreas, às quais a Ciência da Informação se inter-relaciona.

Quanto aos autores brasileiros, Gomez (1990) discute principalmente sobre o que constituiria o domínio da Ciência da Informação:

A Ciência da Informação não se identificaria pela especificação qualitativa de uma ordem de fenômenos de informação como sendo seu objeto, mas pela instauração de um "ponto de vista" organizador de um domínio transdisciplinar. Esse ponto de vista afirma a relação entre uma pragmática social de informação (ou "meta-informação") e os "mundos" de vida, de ação, de conhecimento, agindo na construção dos valores de informação (Gomez, 1990:1).

A autora ressalta a característica, também destacada por Wersig (1991), de que o objeto da Ciência da Informação não se limita à noção de informação. Para ela, o domínio da Ciência da Informação se constituiria a partir de pontos de vista que não se limitariam a uma coisa em si, mas diriam respeito a regras e relações tecidas num contexto social, fruto dos processos e produções simbólicas de uma comunidade. Para isso, a autora ainda enfatiza a necessidade de uma orientação inter- e transdisciplinar ao se encarar o contexto informacional (Gomez, 1990).

Pinheiro e Loureiro (1995), depois de traçarem um panorama da Ciência da Informação no Brasil e no Mundo no artigo Traçados e limites daCiência da Informação, destacam dois aspectos: a dicotomia tecnologia $X$ social, e a influência da pós-modernidade no escopo da área. Para isso, 
retomam a ideia de Saracevic (1995) ao afirmar que a Ciência da Informação oscila entre o humano e o tecnológico, porém a dimensão social humana é a que prevalece. E quanto à influência do fazer científico na contemporaneidade, retomam Wersig (1991), bem como Japiassu (1976) que aborda a epistemologia da complexidade no fazer científico contemporâneo. Esses autores ajudam na ratificação de Pinheiro e Loureiro (1995) de que é preciso olhar a Ciência da Informação sob outro viés, não como uma ciência clássica, já que mesmo com uma prática bem desenvolvida, sua teoria está sendo ensaiada, mas como uma ciência fruto do contexto pós-moderno.

Na década de 2000, os autores mudam um pouco o enfoque da noção de Ciência da Informação. A natureza interdisciplinar da área é notória na maioria das definições, até se estendendo a discussão para os níveis de relação disciplinar: multidisciplinar, interdisciplinar e transdisciplinar, noções bem discutidas no artigo de Pombo (1994). Contudo, o aspecto que mais de se destacou nesse período foi a discussão acerca do papel social da área.

Miranda (2002), ao definir a Ciência da Informação a aproxima do terceiro mundo definido por Popper (1975), que consiste no mundo do conhecimento objetivo. Para ele a Ciência da Informação, mais que uma interdisciplina é uma metaciência, capaz de estudar os fenômenos do registro do conhecimento e trabalhar para aperfeiçoar as formas de produção, uso e armazenamento da informação de forma objetiva e constante. A Ciência da Informação teria assim duas vertentes, associadas ao conhecimento objetivo: uma teórica e outra prática, ambas indissociáveis e interligadas.

Araújo (2003), ao discutir a definição de Ciência da Informação, ressalta dois aspectos: seu caráter social e sua relação com o modelo de ciência pós-moderna. O primeiro aspecto é extensamente justificado pelo autor tanto pela dimensão social da área, como pelo seu diálogo interdisciplinar, ratificados também nas definições institucionais da Capes e CNPq, que entendem a Ciência da Informação como uma ciência social aplicada. No aspecto relacional com a pós-modernidade, o autor retoma outros modelos de desenvolvimento científico até chegar à contemporaneidade, onde a Ciência da Informação, assim como outras ciências que surgiram na segunda metade do século XX, se orientam a partir de uma perspectiva de construção de um novo fazer científico. 
A “ciência pós-moderna” (Santos, 1996) é entendida como o movimento de superação da crise do paradigma científico dominante desde o século XVII, pela superação do modelo de racionalidade cartesiana, de separação do sujeito e do objeto, a busca da ordem, a separabilidade dos elementos constituintes da realidade, movimento esse motivado pelas crises geradas com a evolução e a aplicação do conhecimento científico, tais como as guerras, os regimes totalitários, a poluição e os desastres ecológicos, a exclusão do acesso ao conhecimento, reforço das desigualdades socioeconômicas, a sofisticação dos instrumentos de dominação (Adorno, Horkheimer, 1990). Fazem parte desse movimento de construção de uma "nova ciência” (Santos, 1996, p. 23-35) as contribuições de Einstein (Teoria da Relatividade), da mecânica quântica (Heisenberg \& Bohr), de Godel (Teorema da Incompletude) e de Prigogine (ordem através das flutuações) (Araújo, 2003:6).

Le Coadic (2004), enfatiza o papel social da Ciência da Informação, ressaltando seu caráter de ciência social aplicada, ou seja, que antes de tudo deve responder a uma necessidade social. É claro que para isso, a Ciência da Informação deve utilizar as ferramentas tecnológicas disponíveis e aproveitar-se de sua natureza interdisciplinar para estabelecer diálogos com outras áreas.

Quanto ao objeto de estudo, Le Coadic (2004), contrário à linha de Wersig (1991), que fala de temas e problemas, aponta a informação como elemento propulsor das ações da Ciência da Informação. Estas ações estão relacionadas às propriedades gerais da informação: natureza, gênese e efeitos, que juntas corroboram os processos de construção, uso e armazenagem da informação. Dessa forma, para ele a informação é fluxo, ou seja, só interessa se circula. Ele a compara com o sangue, tanto por precisar circular para exercer sua função, como por ser um elemento vital, que no caso da informação é essencial para o desenvolvimento científico.

Já Capurro e Hjorland (2007), no renomado artigo o Conceito de Informação, também destacam o papel da informação para definição do escopo da Ciência da Informação, contudo apresentam outra perspectiva. Para falar da informação, os autores revisitam todo um arcabouço teórico sobre o termo, chegando, sinteticamente, ao que eles denominam de três paradigmas da informação: o físico, o cognitivo e o social. 
O primeiro se refere a um objeto físico (mensagem ou sinal) que um emissor transmite a um receptor. O segundo relaciona os estudos de Belkin (1978), sobre o estado anômalo do conhecimento, com os de Popper (1975), que aborda perspectiva de estudo dos três mundos. Assim, no paradigma cognitivo a informação é um elemento que provoca transformação nas estruturas mentais do sujeito cognoscente. E por fim, o paradigma social é aquele influenciado pela Hermenêutica de Heidegger (1973) e as propostas de jogos de linguagem de Wittgenstein (1958), que, diferentemente do paradigma anterior, não encaram o sujeito de modo isolado, mas como alguém inserido num contexto social, em que se deve considerar sua relação com o meio e com a comunidade discursiva em que se encontra.

Dentre os três paradigmas apresentados, os autores destacam o último, o paradigma social. Para eles, nenhuma ciência deveria ser identificada pelas suas ferramentas, mas sim pelo seu objeto de estudo; no caso, a informação. Dessa forma, o foco dos profissionais, segundo os autores, não deveria se limitar às tecnologias da área, mas redimensionar o olhar visualizando a Ciência da Informação numa perspectiva social, em que seu objeto de estudo, a informação, é definido em relação às necessidades de uma determinada comunidade discursiva (Capurro; Hjorland, 2007).

\subsection{Síntese da noção de Ciência da Informação}

Depois de analisarmos os textos acima, fazendo as devidas ponderações para cada definição, chegamos a uma proposta de síntese da noção do termo Ciência da Informação:

A Ciência da Informação é uma ciência social aplicada, voltada à resolução de problemas concretos de determinado contexto. Tem a função de resolver as necessidades informacionais das diferentes comunidades discursivas. Demonstra um nítido caráter inter- e para alguns autores até transdisciplinar, no qual dialoga com outras áreas. Já a questão sobre seu objeto de estudo não tem um consenso na área, para uns a informação e o estudo de suas propriedades, natureza e uso, constituem o elemento-chave da Ciência da Informação. Para outros autores, a Ciência da Informação está inserida num contexto pós-moderno, e que por isso teve seus paradigmas científicos alterados. Nesse viés, o mais adequado não seria falar de um objeto científico, mas de temas e problemas da 
área, já que devem ser consideradas as fragmentações e subjetividades do fazer científico da atualidade. Outro ponto polêmico é a importância da tecnologia para a área. Para uns a tecnologia está intimamente ligada ao fazer científico da Ciência da Informação, para outros ela é apenas uma ferramenta no processo e não deve ser superestimada, já que o mais importante é a dimensão social da área.

A síntese da noção de Ciência da Informação nos permite averiguar que, mesmo havendo a concordância dos autores em alguns aspectos, há ainda entraves que atrapalham a delimitação do escopo da área. É claro que temos de ponderar que pelo fato de a Ciência da Informação ter se desenvolvido num momento histórico de mudanças profundas no fazer científico, fica difícil tentar enquadrá-la aos moldes do paradigma científico influenciado pelo cartesianismo e positivismo. Todavia não há como ignorar tais parâmetros, que ainda circundam o fazer científico contemporâneo.

Por isso ao elaborarmos a síntese da noção de Ciência da Informação, procuramos resgatar os principais pontos de vista apresentados, mesmo que conflitantes, já que é da natureza da área esta proposta de um olhar em diferentes perspectivas, o que permite não só maior dinamicidade ao domínio em questão, como uma maior flexibilidade frente às idiossincrasias da área.

\section{CONSIDERAÇÕES FINAIS}

A Ciência da Informação, tanto por sua origem, de certa forma recente, como pelo desenvolvimento de seu escopo, no âmbito das fragmentações e relativizações do contexto pós-moderno, é uma área que ainda está se constituindo. Dessa forma, estudos terminológicos contribuem para a atual discussão sobre o caráter identitário da Ciência da Informação, considerando que na contemporaneidade, mais importante que delimitar o objeto científico da área, ou mesmo definir objetivamente suas fronteiras, é considerar a dinamicidade contextual e as trocas interdisciplinares.

Corroborando a constituição do corpo teórico da área temos a ajuda da Terminologia. Em especial, a Terminologia contemporânea ressalta, mais do que a normalização, o uso dos termos, o que permite avaliar melhor as flutuações de sentido na compreensão identitária da Ciência da Informação. Ao 
invés de prescrever conceitos fechados e isolados, a orientação terminológica contemporânea acaba por ressaltar o papel dos diferentes contextos no uso.

Concluímos, portanto, que a análise terminológica do termo Ciência da Informação contribuiu tanto para observarmos as diferentes perspectivas acerca do que constitui o escopo da área, como verificar os principais traços que corroboram a caracterização identitária da Ciência da Informação, no âmbito da contemporaneidade.

\section{BIBLIOGRAFIA}

ARAÚJO, C. A. A. 2003. A Ciência da Informação como ciência social. Ciência da Informação, Brasília, v. 32, n. 3, 21-27, set./dez.

BARROS, L. A. 2004. Curso básico de terminologia. São Paulo: EDUSP.

BELKIN, N. J. 1978. Information concepts of information for Information Science. Journal of Documentation, v. 34, n.1, 55-85.

BORKO, H. 1968. Information Science: what is it? American Documentation. Washington, v. 19, n.1.

CABRÉ, M. T. 1993. La terminología: teoría, metodología, aplicaciones. Barcelona: Ed. Antártida; Empúries.

CABRÉ, M.T. 1999. La terminología: representación y comunicación. Barcelona: IULAUPF.

CAPURRO, R. \& HJØRLAND, B. 2001. O conceito de informação. Perspectivas em Ciência da Informação, v.12, n.1. Disponível em: < http://www.eci.ufmg.br/pcionline/>. Acesso em: 10 out 11 .

DIAS, C. A. 2000. Terminologia: conceitos e aplicações. Ciência da Informação, Brasília, v. 29, n. 1, 90-92, jan./abr.

FOSKETT, D. J. 1980. Ciência da informação como disciplina emergente; implicações educacionais. In: Ciência da informação on Informática? Rio de Janeiro: Calunga, p. 53-69.

GOMEZ. N. M. G. 1990. O objeto de estudo da Ciência da Informação: paradoxos e desafios. Ciência da Informação, Brasília, v. 19, n. 2, 117-22, jul./dez.

JAPIASSU, H. 1976. Interdisciplinaridade e patologia do saber. Rio de Janeiro: Imago.

LARA, M. L. G. 1996. A representação documentária: em jogo a significação. (Dissertação de Mestrado). São Paulo: ECA-USP.

. 2005. Elementos de terminologia. São Paulo: ECA-USP. (Apostila para uso

didático). Disponível em: <http://infobservatorio.incubadora.fapesp.br/portal/ int_terminol/bibliografia/elemterm2005.doc/view>. Acesso em: 25 out.11. 
2006. Novas relações entre Terminologia e Ciência da Informação na perspectiva de um conceito contemporâneo da informação. DataGramažero, v.7, n.4, ago. Disponível em: <http://www.dgz.org.br/ago06/F_I_art.htm>. Acesso em: 25 out.11.

LE COADIC, Y. F. 2004. A ciência da informação. São Paulo: Briquet Lemos.

MIRANDA, A. 2002. A Ciência da Informação e a Teoria do Conhecimento: um relacionamento necessário. In: AQUINO, M. A. O campo da Ciência da Informação- gênese, conexões e especificidades. João Pessoa: Editora Universitária da UFPB.

PAVEAU, M. A.; SARFATI, G. E. 2006. Fernand Saussure: a teorização da linguística moderna. In:_. As grandes teorias da Linguística: da gramática comparada à pragmática. Trad. De M. R. Gregolim et al. São Carlos: Claraluz.

PINHEIRO, L. V.; LOUREIRO, J. M. M. 1995. Traçados e limites da Ciência da Informação. Ciência da Informação. Brasília, v 24, n.1.

POMBO, O. 1994. Contribuição para um vocabulário sobre interdisciplinaridade. (selecção e organização). In: POMBO, O.; LEVY, T. e GUIMARAES, H. A Interdisciplinaridade: Reflexão e Experiência, 2. ed. (revista e aumentada). Lisboa: Ed. Texto, 92-97.

POPPER, K. R. 1975. Conhecimento objetivo: uma abordagem evolucionária. Belo Horizonte: Itatiaia; São Paulo: Edusp, v. 13. (Espírito de Nosso Tempo).

REY, A. 1979. La Terminologie: noms et notions. Paris: Presses Universitaires de France.

SANTOS, B. S. 1987. Um discurso sobre as ciências. Porto: Afrontamento.

SARACEVIC, T. 1995. A natureza interdisciplinar da ciência da informação. Ciência da Informação, v. 24, n.1.

SMIT, J. W.; TÁLAMO, M. F. G. M.; KOBASHI, N. Y. 2001. A função da terminologia na construção do objeto da Ciência da Informação. DataGramaZero, v.2, n.2, abr. Disponível em: <http://www.dgz.org.br/abr01/Art_03.htm>.Acesso em: 08 out.11.

TÁLAMO, M. F. G. M. 2001. Terminologia e documentação. Tradterm, São Paulo, v. 1, n. 7, 141-151.

; LARA, M. L. G. 2005. O campo da Linguística Documentária. Transinformação, v.18, n. 3, set./dez. Disponível em: < http://revistas.puc-campinas.edu.br/transinfo/ index.php>. Acesso em: 19 out. 2011.

WAZLAWICK, R.S. 2010. Uma reflexão sobre a pesquisa em computação à luz da classificação das ciências e do método científico. Revista de Sisitemas de Informação da FSMA, n.6, p.3-10.

WERSIG, G. 1991. Information Science: the study of postmodern knowledge usage. Information Processing \& Management, v. 29, n. 2, 229-239. 


\section{The notion of Information Science - A Terminological Approach}

Abstract: The comprehension of the identifying characteristics of Information Science is a contemporary necessity observed in the context of postmodernity. The starting point of this study is the terminological analysis of the term Information Science, using the principal procedures for analysis and synthesis in contemporary orientation of the Communicative Theory of Terminology. Analysis of these definitions allows for the main characteristics of the area to be identified, in order to corroborate a better definition of the Information Science field.

Keywords: Information Science; Postmodernity; Terminology.

Recebido em: 06/11/2011

Aprovado em: 11/05/2012 